\title{
How long does it take to initiate a child on long-term invasive ventilation? Results from a Canadian pediatric home ventilation program
}

\author{
Reshma Amin MD MSc ${ }^{1,2}$, Aarti Sayal ${ }^{1}$, Faiza Syed RRT ${ }^{1}$, Cathy Daniels NP-Paed ${ }^{1,2}$, Andrea Hoffman MD³, \\ Theo J Moraes MD PhD ${ }^{1,2}$, Peter Cox $\mathrm{MD}^{2,4}$
}

\begin{abstract}
R Amin, A Sayal, F Syed, et al. How long does it take to initiate a child on long-term invasive ventilation? Results from a Canadian pediatric home ventilation program. Can Respir J 2015;22(2):103-108.
\end{abstract}

OBJECTIVE: To assess the length of stay required to initiate long-term invasive ventilation at the authors' institution, which would inform future interventional strategies to streamline the in-hospital stay for these families. METHODS: A retrospective chart review of children initiated on invasive long-term ventilation via tracheostomy at the authors' acute care centre between January 2005 and December 2013 was performed.

RESULTS: Thirty-five children were initiated on long-term invasive ventilation via tracheostomy at the acute care hospital; 19 (54\%) were male. The median age at time of admission was 0.52 years (interquartile range [IQR] 0.06 to 9.58 years). Musculoskeletal disease $(n=11$ [31\%]) was the most common reason for tracheostomy insertion. Two children died during the hospital admission. Fifteen children were discharged home directly from the acute care hospital and 18 were moved to the rehabilitation hospital. Six are current inpatients of the rehabilitation centre and were never discharged home. Combining the length of stay at the acute care and rehabilitation hospitals for the entire cohort, the median length of stay was 162.0 days (IQR 98.0 to 275.0 days) and 97.0 days (IQR 69.0 to 210.0 days), respectively, from the time of tracheostomy insertion.

CONCLUSIONS: The median length of stay from the initiation of invasive long-term ventilation to discharge home from the rehabilitation hospital was somewhat long compared with other ventilation programs worldwide. Additionally, approximately $20 \%$ of the cohort never transitioned home. There is a timely need to benchmark across the country and internationally, to identify and implement strategies for cohesive, coordinated care for these children to decrease overall length of stay.

Key Words: Length of stay; Pediatric; Ventilation
There has been a significant increase in the pediatric long-term home mechanical ventilation population in the past few decades (1-19). This significant increase is due to advances in medical care and assistive technologies, partnered with an increasing number of decisions being made to institute long-term ventilation in children who would have been previously palliated $(18,20)$. Although critical when discussing the initiation of long-term ventilation with children and their caregivers, there is limited literature regarding the ideal process within an acute care facility for the initiation of ventilation as well as the ideal timelines for final discharge home $(3,21,22)$.

There have been a handful of published studies from various countries around the world reporting on length of hospital stay for children initiated on long-term invasive ventilation via tracheostomy. The reported median length of stay is broad, ranging from 46 days to 9.6 months $(14,17,23-27)$. However, Canadian data are notably absent, despite two recent publications describing pediatric ventilation programs in the country $(1,19)$. Regional information regarding length of stay and associated variables is vital to understanding the
Combien de temps faut-il pour amorcer une ventilation invasive à long terme chez l'enfant : les résultats d'un programme canadien de ventilation pédiatrique à domicile

OBJECTIF : Évaluer la durée d'hospitalisation nécessaire pour amorcer une ventilation invasive à long terme à l'établissement des auteurs, afin d'étayer les futures stratégies d'intervention et d'harmoniser le séjour hospitalier pour ces familles.

MÉTHODOLOGIE : Dans leur établissement, les auteurs ont procédé à l'analyse rétrospective des dossiers d'enfants chez qui on avait amorcé une ventilation à long terme par trachéotomie entre janvier 2005 et décembre 2013. RÉSULTATS : À l'hôpital de soins aigus, on a amorcé une ventilation invasive à long terme par trachéotomie chez 35 enfants, dont 19 (54\%) de sexe masculin. Ces enfants avaient un âge médian de 0,52 ans (plage interquartile [PIQ] de 0,06 à 9,58 ans) à l'admission. Une maladie musculosquelettique $(\mathrm{n}=11$ [31\%]) expliquait la plupart des trachéotomies. Deux enfants sont décédés pendant l'hospitalisation. Quinze ont obtenu leur congé à domicile directement de l'hôpital de soins aigus et 18 ont été transférés à un hôpital de réadaptation. Six sont actuellement hospitalisés au centre de réadaptation et n'ont jamais obtenu leur congé à domicile. Si on combine la durée d'hospitalisation aux hôpitaux de soins aigus et de réadaptation pour l'ensemble de la cohorte, la durée de séjour médiane était de 162,0 jours (PIQ de 98,0 à 275,0 jours) et de 97,0 jours (PIQ 69,0 à 210,0 jours), respectivement, à compter du moment de la trachéotomie.

CONCLUSIONS : La durée d'hospitalisation médiane en réadaptation entre l'amorce de la ventilation invasive à long terme et le congé à domicile était plutôt longue par rapport aux autres programmes de ventilation dans le monde. De plus, environ $20 \%$ de la cohorte ne sont jamais retournés à la maison. Il est urgent d'obtenir des normes au pays et sur la scène internationale, ainsi que d'établir et d'adopter des stratégies pour offrir des soins homogènes et coordonnés à ces enfants et ainsi réduire la durée globale de leur hospitalisation.

pediatric transition from hospital to home for children on long-term mechanical ventilation (LTMV). These factors also account heavily into the cost of care, an issue that is receiving more attention in the setting of the complex medical child (28). Examining these processes will enable us to identify trends and to summarize clinical outcomes along this clinical pathway. Furthermore, policy to implement best practice and improve the quality of life of patients and their families is contingent on informing interventional strategies to decrease length of stay by providing comprehensive, coordinated care.

Accordingly, the aim of the present study was to retrospectively review the process of the initiation of LTMV in our tertiary academic centre, with a focus on length of stay to inform future interventional strategies to streamline the in-hospital stay for these children and their families.

\section{METHODS}

A prospective clinical database was used for a retrospective chart review of pediatric patients $<18$ years of age who were initiated on

\footnotetext{
${ }^{1}$ Division of Respiratory Medicine, The Hospital for Sick Children; ${ }^{2}$ Department of Pediatrics, University of Toronto; ${ }^{3}$ Division of Pediatrics, Holland Bloorview Rehabilitation Hospital; ${ }^{4}$ Division of Paediatric Critical Care Medicine, The Hospital for Sick Children, Toronto, Ontario Correspondence: Dr Reshma Amin, 4539, Hill Wing, Division of Respiratory Medicine, The Hospital for Sick Children, 555 University Avenue, Toronto, Ontario M5G 1X8. Telephone 416-813-6346, fax 416-813-6246, e-mail reshma.amin@sickkids.ca
} 
TABLE 1

Baseline demographics of the study participants $(n=35)$

\begin{tabular}{lc}
\hline Variable & $19(54)$ \\
\hline Male sex & $0.52(0.1-9.6)$ \\
Age at admission to acute care hospital ${ }^{*}$ during which & \\
tracheostomy was performed, years, median (IQR) & \\
Age at initiation of ventilation, years, median (IQR) & $0.72(0.1-9.6)$ \\
Reason for admission to the acute care hospital & \\
Postoperative cardiac surgery & $6(17)$ \\
Acute respiratory failure & $14(40)$ \\
Chronic respiratory failure & $11(31)$ \\
Upper airway obstruction & $2(6)$ \\
Other (refractory status epilepticus, complex cardiac & $2(6)$ \\
$\quad$ disease) & \\
Number of extubation attempts & \\
0 & $9(26)$ \\
1 & $4(11)$ \\
2 & $5(14)$ \\
3 & $6(17)$ \\
$>3$ & $8(23)$ \\
Reason for tracheostomy & \\
Failure to wean because of pulmonary disease & $6(17)$ \\
Upper airway obstruction & $8(23)$ \\
Central nervous system/spinal lesion or injury & $6(17)$ \\
Neuromuscular disease & $11(31)$ \\
Congenital central hypoventilation syndrome & $3(9)$ \\
Tracheobronchial toileting & $1(3)$ \\
\hline
\end{tabular}

Data presented as $n(\%)$ unless otherwise indicated. ${ }^{*}$ The Hospital for Sick Children, Toronto, Ontario. IQR Interquartile range

LTMV via a tracheostomy at The Hospital for Sick Children (SickKids, Toronto, Ontario) between January 1, 2005 and December 31, 2013. For the present study, LTMV was defined as the daily use of invasive mechanical ventilation after tracheosotomy insertion. Ventilation was initiated in either the neonatal intensive care unit (NICU) or pediatric intensive care unit (PICU).

Health care records were reviewed to obtain the following information pertaining to health care use beginning at admission to SickKids between 2005 and 2013 inclusive: date of admission; reason for admission to SickKids (the 'acute care' hospital); admission to NICU/PICU/ ward; date of initiation of ventilation; number of extubation attempts; date of tracheostomy insertion; reason for tracheostomy insertion; diagnosis (adapted from Wallis et al [4]); date of respirology consultation for LTMV; date of first tracheostomy change; date of first education session; date of last education session; discharge date from the acute care hospital; number of hours on ventilation support at discharge; use of oxygen at time of discharge; discharge destination; number of hours of nursing support/week; duration of stay at the Holland Bloorview Rehabilitation Hospital (the 'rehabilitation hospital', Toronto, Ontario); date of death (if applicable); location of death (if applicable); current location of residence; date of first readmission to the acute care hospital; cause of first readmission to the acute care hospital; and emergency room visits after discharge. If the patient was never discharged home, the last date of the study (ie, December 31, 2013) was considered to be the 'discharge date' to calculate length of stay. The Home Ventilation Program at SickKids is an interprofessional inpatient and outpatient service that provides consultation and follow-up to all children at risk for and requiring LTMV at home. When the decision has been made to pursue invasive LTMV at home, an extensive training program is developed for the child and family, and begins for a minimum of two trained family caregivers in the home. It is recommended that an awake, trained caregiver care for these children $24 \mathrm{~h}$ per day at home. Some of the families complete the training during the acute hospital admission and others will complete the training at the rehabilitation hospital.
TABLE 2

Primary reasons for initiation of long-term invasive mechanical ventilation in the study participants

\begin{tabular}{lll}
\hline Reason for ventilation & Major subgroup & $\mathbf{n}$ \\
\hline $\begin{array}{l}\text { Central nervous } \\
\text { system (n=11 [31\%]) }\end{array}$ & Birth injury/cerebral & 1 \\
& Spinal injury & 1 \\
& Acquired central hypoventilation & 3 \\
& syndrome & \\
& Congenital central hypoventilation & 3 \\
& syndrome & \\
Central nervous system tumour & 3 \\
(n=13 [37\%]) & Duchenne muscular dystrophy & 1 \\
& Other dystrophy & 5 \\
& Spinal muscular atrophy type 1 & 1 \\
& Spinal muscular atrophy type 2 & 1 \\
Respiratory disease & Other myopathy & 5 \\
(n=11 [31\%]) & Chronic lung disease & 2 \\
& Upper airway obstruction & 4 \\
& Airway malacia & 2 \\
& Pulmonary hypoplasia & 1 \\
\hline
\end{tabular}

Descriptive statistics were used to summarize the entire study population. Results were presented as frequencies or medians and interquartile ranges (IQRs) as appropriate. The Mann-Whitney $U$ test was used to compare nonparametric continuous variables. The $\chi^{2}$ test was used to compare categorical variables; $\mathrm{P}<0.05$ was considered to be statistically significant. Graph Pad Prism (GraphPad, USA) was used for the statistical analysis.

The Research Ethics Board at SickKids and Holland Bloorview Rehabilitation Hospital reviewed and approved the study protocol. Because the present study was retrospective, without any identifying data, the research ethics boards deemed informed consent to be unnecessary.

\section{RESULTS}

Between January 1, 2005 and December 31, 2013, 35 patients (19 [54\%] male) were initiated on LTMV via tracheostomy at the acute care hospital. The baseline demographics of this cohort are summarized in Table 1 . The median age at time of admission was 0.52 years (IQR 0.06 to 9.58 years). Eighty-three percent $(n=29)$ of the patients had an acute admission, while $17 \%(n=6)$ had an elective admission. In the cohort, 27 (77\%) were initiated on ventilation in the PICU and eight (23\%) were initiated in the NICU. All of the patients who were initiated on LTMV had yet to go home after birth. Nine $(26 \%)$ of the cohort did not undergo any extubation attempts and only eight (23\%) of the cohort underwent $>3$ attempts. Musculoskeletal (MSK) disease $(\mathrm{n}=11[31 \%])$ was the most common reason for tracheostomy insertion. Respiratory medicine was consulted in 29 of 35 (83\%) cases before tracheostomy insertion.

Table 2 lists the reasons for LTMV. The primary diagnoses were categorized into three main groups: central nervous system $(n=11)$, MSK disease $(n=13)$ and respiratory disease $(n=11)$. The most common diagnosis was MSK disease $(n=13$ [37\%]). Chronic lung disease secondary to prematurity accounted for $3 \%$ of the cohort.

Table 3 summarizes the course in the acute care hospital. Two children died during the hospital admission. The median number of days in the acute care hospital from tracheostomy insertion to discharge was 62.0 days (IQR 26.5 to 85.5 days) for the remaining 33 children. Only 15 families completed caregiver training during the acute care hospital stay and were discharged directly home; the remaining 18 (55\%) were discharged to the rehabilitation hospital. The median number of days in the acute care hospital, from tracheostomy insertion to discharge directly home, was 79.0 days (IQR 57.8 to 93.8 days). For the subgroup that was discharged to the rehabilitation hospital, the median number of days in the acute care hospital from tracheostomy insertion 
TABLE 3

The hospital course at the tertiary acute care hospital* for the study cohort $(n=35)$

\begin{tabular}{|c|c|}
\hline Variable & \\
\hline Admission to initiation of ventilation, days & $0(0-29.5)$ \\
\hline Initiation of ventilation to tracheostomy insertion, days & $54.0(22.0-110.0)$ \\
\hline $\begin{array}{l}\text { Tracheostomy insertion to discharge from the acute } \\
\text { care hospital (all patients) }\end{array}$ & $62.0(26.5-85.5)$ \\
\hline $\begin{array}{l}\text { Admission to discharge from the acute care hospital, } \\
\text { days }\end{array}$ & $125(72.5-195.0)$ \\
\hline $\begin{array}{l}\text { At time of discharge from the acute care hospital, } \\
\text { home ventilation training complete, } n / n\end{array}$ & $15 / 33$ \\
\hline \multicolumn{2}{|l|}{ Discharge destination, $\mathrm{n}(\%)$} \\
\hline Home & $15(45)$ \\
\hline 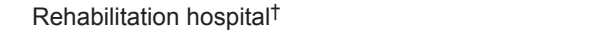 & $18(55)$ \\
\hline
\end{tabular}

Data presented as median (interquartile range) unless otherwise indicated. *The Hospital for Sick Children; ${ }^{+}$Holland Bloorview Rehabilitation Hospital, Toronto, Ontario

to discharge was 37.0 days (IQR 13.0 to 71.0 days). The length of stay was not significantly different between the two groups $(\mathrm{P}=0.07)$. At the time of discharge from the acute care hospital, $16(49 \%)$ children were ventilated $24 \mathrm{~h}$ per day, five $(15 \%)$ were ventilated $18 \mathrm{~h}$ to $20 \mathrm{~h}$ per day, and the remaining $12(36 \%)$ children were only nocturnally ventilated.

Eighteen children were transferred to the rehabilitation hospital from the acute care facility for ongoing caregiver education and training. At the conclusion of the study, six (17\% of the original cohort) remain as inpatients at the rehabilitation hospital. The median duration of stay at the rehabilitation hospital was 202.0 days (IQR 98.0 to 1052.0 days). For the 18 children transferred to the rehabilitation hospital, the length of stay, median from admission to the acute care hospital to discharge home for the 12 of 18 children that were discharged home was 240.0 days (IQR 93.5 to 419.5 days). Combining the duration of stay at the acute care and rehabilitation hospitals for the entire cohort, the median length of stay was 162.0 days (IQR 98.0 to 275.0 days) and 97.0 days (IQR 69.0 to 210.0 days) from the time of tracheostomy insertion (Table 4).

Table 5 summarizes health care resource utilization after discharge home. The median number of days between discharge and first admission to the acute care hospital was 149.0 days (IQR 43.0 to 348.0 days). There have been a total of six deaths. Two children died in hospital during the admission during which the tracheostomy was inserted; one child died of a cardiopulmonary arrest and the second died of progressive brainstem compression in the setting of a brainstem tumour. Of the remaining four children, three died at home. Two children died of respiratory failure and one died because of an accidental decannulation. The fourth child died in hospital because of acute respiratory failure after readmission. The overall duration between tracheostomy insertion and death was 258.0 days (IQR 90.8 to 479.0 days). For the children who died after discharge, the median age at the time of death was 1.96 years (IQR 1.6 to 7.2 years). There was no difference in the age of initiation, the length of original hospital stay, reason for ventilation or duration of ventilation per $24 \mathrm{~h}$ period between the children in the cohort who died and those that remain alive.

\section{DISCUSSION}

To our knowledge, we are reporting the first Canadian pediatric data describing the length of stay for children initiated on LTMV via tracheostomy. If we considered the median length of stay in our acute care hospital only, it would be somewhat misleading because $>50 \%$ of our cohort progress to prolonged stays at a rehabilitation hospital. Therefore, median length of stay of 195 days (IQR 114.0 to 303.3 days) for both the acute and rehabilitation hospital is a more accurate estimate for comparison with the international literature (Table 6). Based on the available literature, length of stay in our centre appears to be

\section{TABLE 4}

\section{Outcomes of patients discharged to the rehabilitation} hospital* $^{*}(\mathrm{n}=18)$

\begin{tabular}{|c|c|}
\hline \multicolumn{2}{|l|}{ Current location of residence, $\mathrm{n}(\%)$} \\
\hline \multicolumn{2}{|l|}{ Rehabilitation hospital } \\
\hline Home & $12(67)$ \\
\hline Duration of stay at the rehabilitation hospital, days & $202(98.0-1052.0)$ \\
\hline $\begin{array}{l}\text { Length of stay from acute care hospital }{ }^{\dagger} \text { admission to } \\
\text { discharge home from the rehabilitation hospital, days }\end{array}$ & $240.0(93.5-419.5)$ \\
\hline $\begin{array}{l}\text { Length of stay from acute care hospital admission } \\
\text { to discharge home for all patients, days }\end{array}$ & $162.0(98.0-275.0)$ \\
\hline $\begin{array}{l}\text { Length of stay from tracheostomy insertion to } \\
\text { discharge home for all patients, days }\end{array}$ & $97.0(69.0-210.0)$ \\
\hline
\end{tabular}

\section{TABLE 5}

Health care resource utilization of the study cohort after discharge home $(\mathbf{n}=\mathbf{2 7})$

\begin{tabular}{ll}
\hline $\begin{array}{l}\text { Days between discharge home and first admission to } \\
\text { hospital }\end{array}$ & $149.0(0-1464)$ \\
Admissions per year on ventilation & $0.7(0-8)$ \\
Days in hospital per year on ventilation & $0.1(0-6.3)$ \\
Days in PICU per year on ventilation & $0.1(0-6.3)$ \\
Emergency room visits per year on ventilation & $0.2(0-8.5)$
\end{tabular}

Data presented as median (interquartile range). PICU Pediatric intensive care unit

longer than in the United States, Turkey and Italy, but shorter than in the United Kingdom (14,17,23-26). Tearl et al (26) reported the results of an intervention in which a dedicated respiratory therapist discharge coordinator provides education and coordinates discharge planning for these patients. Although there was no significant difference in length of stay from the intervention, there was a trend toward improvement, with length of stay improving postintervention from a mean ( \pm SD) of $82 \pm 45$ days to $48 \pm 44$ days (26). Therefore, this suggests that the discharge process for a child initiated on LTMV would benefit from a clear, transparent flow process that crosses institutions (ie, acute and rehabilitation centres) and is facilitated by a key hospital health care professional.

Although streamlining care is paramount, addressing the barriers to discharge home for these children is also essential. Several studies report prolonged length of stay after medical stability has been achieved and caregiver training is completed because of other contributing factors $(14,25,27)$. There have been a handful of studies to date that have reported on the barriers to discharge for this population $(14,17,24,25,29,30)$. These barriers appear to fall into seven categories: lack of suitable housing; waiting for equipment funding; delays in receiving the equipment for the home; social issues related to the family; community caregivers; lack of a coordinated approach to discharge; and delays in organizational decision making $(14,17,24,25,29,30)$. The formal identification of barriers to discharge in our cohort was limited because of the retrospective nature of our study and the lack of clear documentation of these issues in the medical chart. However, a major barrier to discharge at our institution involves the availability of skilled community caregivers. In Ontario, the government funds $43 \mathrm{~h}$ of shift nursing for these children to support the primary caregivers. Only nurses are permitted to care for children receiving invasive ventilation in the community, unlike for ventilator-assisted adults in the community. However, trained nurses are not always readily available and, when they are, their training may be insufficient, thus contributing to delays in discharge. 
TABLE 6

Reported of lengths of stay for the initiation of long-term ventilation from the published literature

\begin{tabular}{|c|c|c|c|c|}
\hline $\begin{array}{l}\text { Author (reference), year; } \\
\text { country }\end{array}$ & Study population & Sample size & Length of stay & Discharge destination \\
\hline Appierto et al (23), 2002; Italy & $\begin{array}{l}\text { Central nervous system (26\%) } \\
\text { Upper airway (26\%) } \\
\text { Spinal muscular atrophy }(22 \%) \\
\text { Other myopathies }(6.5 \%) \\
\text { Bronchopulmonary dysplasia }(6.5 \%) \\
\text { Tracheomalacia }(6.5 \%) \\
\text { CCHS }(4.3 \%) \\
\text { Congenital scoliosis }(2.2 \%)\end{array}$ & $\begin{array}{l}\text { Tracheostomy }(n=46) ; \\
\text { tracheostomy and } \\
\text { ventilation }(n=34 / 46)\end{array}$ & 109.5 days (IQR 54-214 days) & $100 \%$ discharged home \\
\hline $\begin{array}{l}\text { Graf et al (24), 2008; } \\
\text { United States }\end{array}$ & $\begin{array}{l}\text { Reason for tracheostomy: } \\
\text { Inadequate airway protection (37\%) } \\
\text { Chronic lung disease }(23 \%) \\
\text { Airway obstruction }(25 \%) \\
\text { Central hypoventilation }(9 \%) \\
\text { Neuromuscular disease }(6 \%)\end{array}$ & $\begin{array}{l}\text { Tracheostomy only }(n=70) \text {; } \\
\text { tracheostomy and } \\
\text { ventilation }(n=33 / 70)\end{array}$ & Median 46 days & $81 \%$ discharged home \\
\hline $\begin{array}{l}\text { DeWitt et al (25),1993; } \\
\text { United States }\end{array}$ & $\begin{array}{l}\text { Initiated on long-term ventilation: } \\
\text { Muscle weakness }(65 \%) \\
\text { Central hypoventilation }(20 \%) \\
\text { Chronic lung disease }(15 \%)\end{array}$ & $\mathrm{n}=54$ & $\begin{array}{l}\text { Time from medical stability } \\
\text { to discharge, mean } \pm S D \\
118 \pm 144 \text { days }\end{array}$ & $\begin{array}{l}\text { 51/54 discharged home; } \\
3 / 54 \text { in foster care }\end{array}$ \\
\hline $\begin{array}{l}\text { Edwards et al (14), 2005; } \\
\text { United Kingdom }\end{array}$ & $\begin{array}{l}\text { Chronic lung disease }(31 \%) \\
\text { Neuromuscular disease }(18 \%) \\
\text { Central nervous system }(3 \%) \\
\text { Trachebronchomalacia }(15 \%) \\
\text { Metabolic disorder }(5 \%) \\
\text { Other }(28 \%)\end{array}$ & $n=39$ & $\begin{array}{l}\text { Median } 9.6 \text { months } \\
\text { (range } 3.6 \text { months to } \\
3.5 \text { years) }\end{array}$ & $\begin{array}{l}\text { 35/39 discharged home; } \\
\text { 4/39 remained in hospital }\end{array}$ \\
\hline $\begin{array}{l}\text { Fraser et al (27),1998; } \\
\text { United Kingdom }\end{array}$ & $\begin{array}{l}\text { Chronic lung disease }(10 \%) \\
\text { Central nervous system (23\%) } \\
\text { Respiratory (15\%) } \\
\text { Neuromuscular }(8 \%) \\
\text { Skeletal dysplasia }(8 \%) \\
\text { Other }(36 \%)\end{array}$ & $\mathrm{n}=40$ & $\begin{array}{l}\text { Median } 78 \text { days } \\
\text { (IQR 44-254 days) from } \\
\text { tracheostomy to discharge }\end{array}$ & Unclear \\
\hline Oktem et al (17), 2008; Turkey & $\begin{array}{l}\text { Central nervous system }(21 \%) \\
\text { Chronic lung disease }(62 \%) \\
\text { Neuromuscular disorders }(18 \%)\end{array}$ & $\begin{array}{l}\text { Tracheostomy only }(n=34) \text {; } \\
\text { tracheostomy and } \\
\text { ventilation }(n=11 / 34)\end{array}$ & Median 64 days & Not specified \\
\hline $\begin{array}{l}\text { Tearl et al (26), 2006; } \\
\text { United States }\end{array}$ & $\begin{array}{l}\text { Airway obstruction }(36 \%) \\
\text { Neuromuscular disorders (32\%) } \\
\text { Chronic lung disease }(31 \%)\end{array}$ & $n=74$ & $\begin{array}{l}\text { Preintervention: mean } \pm \text { SD } \\
82 \pm 45 \text { days } \\
\text { Postintervention: mean } \pm \text { SD } \\
48 \pm 44 \text { days }\end{array}$ & $\begin{array}{l}100 \% \text { of patients discharged } \\
\text { home }\end{array}$ \\
\hline
\end{tabular}

CCHS Congenital central hypoventilation syndrome; IQR Interquartile range

The most common medical condition mandating the initiation of LTMV in our cohort was MSK disease (37\% [n=13]). The percentage of children with MSK disease within ventilation programs around the world is broad, ranging from $6 \%$ to $65 \%$, with our program falling somewhere in the middle $(14,17,23-27)$. These differences likely reflect differing years of study and dissimilar study designs, as well as discrepancies in international clinical management. The indications for invasive ventilation as first-line therapy for children with chronic lung disease, MSK disease and/or young age are likely based on "varying interpretations of acceptable risks of noninvasive ventilation" as well as the underlying influence of health care costs (19). As a result of different health care systems, some centres may face more pressure to proceed with tracheostomy and invasive ventilation to facilitate discharge instead of observing and waiting for potential improvement over a defined period of time (19). Furthermore, unlike in the adult intensive care unit, the overall rate of tracheostomy in PICUs across Canada is $<1.5 \%$ (31). In contrast to adults, tracheostomies are rarely performed for prolonged intubation and ventilation in children, and is often only performed when it is clear that a child will require prolonged ventilation at home (31). Therefore, understanding the regional population and practices is essential for current planning resource allocation until such a time when ventilatory modality decision making becomes streamlined across programs, regions and nations.

Thirty-five children were initiated on LTMV and $82 \%$ were successfully transitioned home. However, six (17\%) children currently remain inpatients of the rehabilitation hospital several years later. For these children, the families believed that they were unable to manage the care required for their child on LTMV based on the existing community supports available to them. Although a family can never be completely prepared for 'what life will be like' caring for a child requiring invasive ventilation, the patient and their family need to have a clear understanding of the potential benefits of LTMV at home for their child as well as the risks, care needs and effects on the family before tracheostomy insertion. This is a major decision for families, and adequate time is needed to ensure all of the relevant information is provided to allow them appropriate planning and the ability to provide informed consent. In our cohort, six children did not receive a consultation with respiratory medicine before tracheostomy; however, none of these patients became long-term residents of the rehabilitation hospital. Four children are currently living at home and two have died. An early respiratory medicine consultation in liason 
with the local home ventilation team is recommended for these children; however, it is not yet clear as to whether this will help to ensure more children managed on LTMV will ultimately be cared for at home.

In this particular cohort, after the initiation of LTMV, the health care expenditures based on our institutional costs appeared to be relatively low. However, there are a couple of factors that may be contributing to the significant underestimation of the 'true' health care costs for these children. In the present study, we investigated the hospital admission, emergency room visits and clinic visits at our acute care tertiary centre only. Our ventilation program services a large catchment area, with many families travelling $>50 \mathrm{~km}$ to our institution (19). Therefore, these children may have also received care from their local community hospital or another tertiary pediatric centre; these hospital expenditures have not been accounted for in our study. Additionally, Cohen et al (32) recently demonstrated that medically complex children, including a subset supported with medical technology, account for $0.67 \%$ of the pediatric population in Ontario, but account for $32.7 \%$ of all health care expenditures (32). Additionally, in the subset of children using medical technology, home care costs were the highest source of health care costs and were well above the costs associated with acute care (32). These medically complex children, such as this LTMV cohort, have decreased acute care costs but profoundly high home care costs that we did not account for in our study. We also did not account for the costs of the ventilators and the ventilator supplies grants provided by the Ministry of Health and Long-term Care in Ontario nor did we account for private, out-ofpocket costs these families faced.

Our study had several limitations. Given that it was a single-centre study, our results may not be generalizable to other centres. The Canadian centres have different clinical programs for initiating and discharging children home on invasive ventilation, varying caregiver training procedures, and different provincial resources and supports for caregivers, all of which could affect clinical outcomes. Presently, a national database of Canadian children requiring LTMV does not exist. Given the relatively small size of the pediatric population receiving LTMV at home, a national registry is needed to review clinical outcomes across the country, standardize management and advance the care of this medically fragile population. Second, our report of health care utilization was limited as described above. We have likely underestimated the health care utilization of our cohort because we did not include primary care visits, home care expenditures or hospitalizations at other acute care hospitals in the cost analysis. Future

\section{REFERENCES}

1. McDougall CM, Adderley RJ, Wensley DF, Seear MD. Long-term ventilation in children: Longitudinal trends and outcomes. Arch Dis Child 2013;989:660-5.

2. Jardine E, O'Toole M, Paton JY, Wallis C. Current status of long term ventilation of children in the United Kingdom: Questionnaire survey. BMJ 1999;3187179:295-9.

3. Jardine E, Wallis C. Core guidelines for the discharge home of the child on long-term assisted ventilation in the United Kingdom. UK Working Party on Paediatric Long Term Ventilation. Thorax 1998;539:762-7.

4. Wallis C, Paton JY, Beaton S, Jardine E. Children on long-term ventilatory support: 10 years of progress. Arch Dis Child 2011;9611:998-1002.

5. Graham RJ, Fleegler EW, Robinson WM. Chronic ventilator need in the community: A 2005 pediatric census of Massachusetts. Pediatrics 2007;1196:e1280-7.

6. Paulides FM, Plotz FB, Verweij-van den Oudenrijn LP, van Gestel JP, Kampelmacher MJ. Thirty years of home mechanical ventilation in children: Escalating need for pediatric intensive care beds. Intens Care Med 2012;385:847-52.

7. Robinson RO. Ventilator dependency in the United Kingdom. Arch Dis Child 1990;6511:1235-6.

8. Gowans M, Keenan HT, Bratton SL. The population prevalence of children receiving invasive home ventilation in Utah. Pediatr Pulmonol 2007;423:231-6. directions will include a provincial and, subsequently, national review of the health care utilization of invasively ventilated children using health care administration databases. Third, given the retrospective study design, while the major issue of length of stay was addressed, there were limited data available with regard to barriers to discharge. However, clinically, a major barrier to discharge in our program is the availability and competencies of community caregivers.

\section{CONCLUSION}

The median length of stay from the initiation of LTMV to discharge home from our rehabilitation hospital was somewhat long compared with other international programs. Additionally, approximately 20\% of our cohort never transitioned home and remains in long-term institutional care. A major barrier to discharge was the lack of trained and available community care providers. There is a timely need to benchmark across the country and internationally and to also implement some of the identified strategies for cohesive, coordinated care for these children to decrease overall length of stay. Standardized management for these children nationally and internationally is needed to advance the care of this medically fragile population.

AUTHOR CONTRIBUTIONS: RA was involved in the development and conception of the study design, data collection, analysis of the results, writing the initial draft of the manuscript and approval the final manuscript as submitted. AS was involved in data collection, interpretation of the results, editing of the manuscript and approval of the final manuscript as submitted. FS was involved in the development and conception of the study design, editing of the initial draft of the manuscript and approval the final manuscript as submitted. CD was involved in the development and conception of the study design, editing of the initial draft of the manuscript and approval the final manuscript as submitted. AH was involved in data collection, editing of the manuscript and approval the final manuscript as submitted. TJM was involved in the interpretation of the results, editing of the manuscript and approval of the final manuscript as submitted. PC was involved in the development and conception of the study design, editing of the initial draft of the manuscript and approval of the final manuscript as submitted. All authors agree to be accountable for all aspects of the work.

DISCLOSURES: The authors have no financial disclosures or conflicts of interest to declare.

9. Fauroux B, Boffa C, Desguerre I, Estournet B, Trang H. Long-term noninvasive mechanical ventilation for children at home: A national survey. Pediatr Pulmonol 2003;352:119-25.

10. Fauroux B, Sardet A, Foret D. Home treatment for chronic respiratory failure in children: A prospective study. Eur Respir J 1995;812:2062-66.

11. Racca F, Bonati M, Del Sorbo L, et al. Invasive and non-invasive long-term mechanical ventilation in Italian children. Minerva Anestesiol 2011;779:892-901.

12. Ottonello G, Ferrari I, Pirroddi IM, et al. Home mechanical ventilation in children: Retrospective survey of a pediatric population. Pediatr Int 2007;496:801-5.

13. Kamm M, Burger R, Rimensberger P, Knoblauch A, Hammer J. Survey of children supported by long-term mechanical ventilation in Switzerland. Swiss Med Wkly 2001;13119-20:261-6.

14. Edwards EA, Hsiao K, Nixon GM. Paediatric home ventilatory support: The Auckland experience. J Paediatr Child Health 2005;4112:652-8.

15. Tibballs J, Henning RD. Noninvasive ventilatory strategies in the management of a newborn infant and three children with congenital central hypoventilation syndrome. Pediatr Pulmonol 2003;366:544-8.

16. Bertrand P, Fehlmann E, Lizama M, Holmgren N, Silva M, Sanchez I. [Home ventilatory assistance in Chilean children: 12 years' experience]. Arch Bronconeumol 2006;424:165-70. 
17. Oktem S, Ersu R, Uyan ZS, et al. Home ventilation for children with chronic respiratory failure in Istanbul. Respiration 2008;761:76-81.

18. Cohen E, Kuo DZ, Agrawal R, et al. Children with medical complexity: An emerging population for clinical and research initiatives. Pediatrics 2011;1273:529-38.

19. Amin R, Sayal P, Syed F, Chaves A, Moraes TJ, Maclusky I. Pediatric long-term home mechanical ventilation: Twenty years of follow-up from one Canadian center. Pediatr Pulmonol 2014:49:816-24.

20. Eiser C, Morse R. Quality-of-life measures in chronic diseases of childhood. Health Technol Assess 2001;54:1-157.

21. Tamasitis J, Shesser L. A hospital-to-home program for ventilatordependent children sets the standard of care. AARC Times 2012:44-52.

22. Halley GC. Getting children home on long term ventilation. Paediatr Child Health 2012;2212:541-3.

23. Appierto L, Cori M, Bianchi R, et al. Home care for chronic respiratory failure in children: 15 years experience. Paediatr Anaesth 2002;124:345-50.

24. Graf JM, Montagnino BA, Hueckel R, McPherson ML. Children with new tracheostomies: Planning for family education and common impediments to discharge. Pediatr Pulmonol 2008;438:788-94.
25. DeWitt PK, Jansen MT, Ward SL, Keens TG. Obstacles to discharge of ventilator-assisted children from the hospital to home. Chest 1993;1035:1560-5.

26. Tearl DK, Cox TJ, Hertzog JH. Hospital discharge of respiratorytechnology-dependent children: Role of a dedicated respiratory care discharge coordinator. Respir Care 2006;517:744-9.

27. Fraser J, Henrichsen T, Mok Q, Tasker RC. Prolonged mechanical ventilation as a consequence of acute illness. Arch Dis Child 1998;783:253-6.

28. Cohen EF. Caring for children with medical complexity: Definitions, challenges and solutions. Curr Pediatr Rev 2012;82:93-102.

29. Goldberg AI, Frownfelter D. The Ventilator-assisted Individuals Study. Chest 1990;982:428-33.

30. Noyes J. Barriers that delay children and young people who are dependent on mechanical ventilators from being discharged from hospital. J Clin Nurs 2002;111:2-11.

31. Principi T, Morrison GC, Matsui DM, et al. Elective tracheostomy in mechanically ventilated children in Canada. Intens Care Med 2008;348:1498-502.

32. Cohen E, Berry JG, Camacho X, Anderson G, Wodchis W, Guttmann A. Patterns and costs of health care use of children with medical complexity. Pediatrics 2012;1306:e1463-70. 


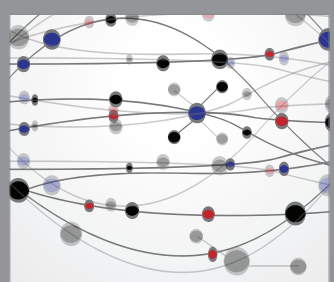

The Scientific World Journal
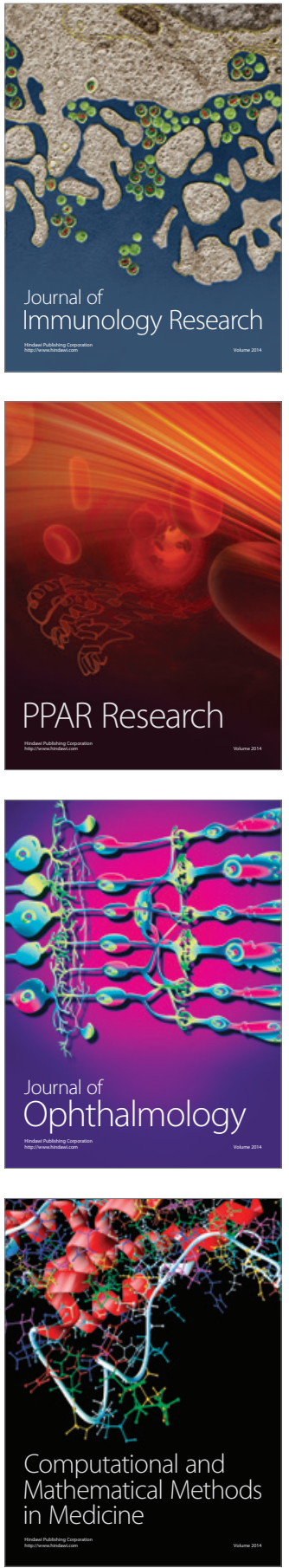

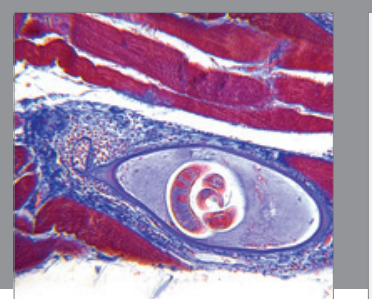

Gastroenterology Research and Practice

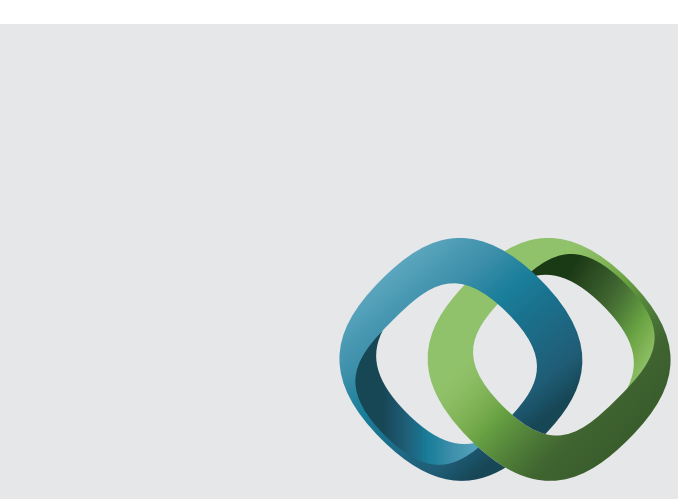

\section{Hindawi}

Submit your manuscripts at

http://www.hindawi.com
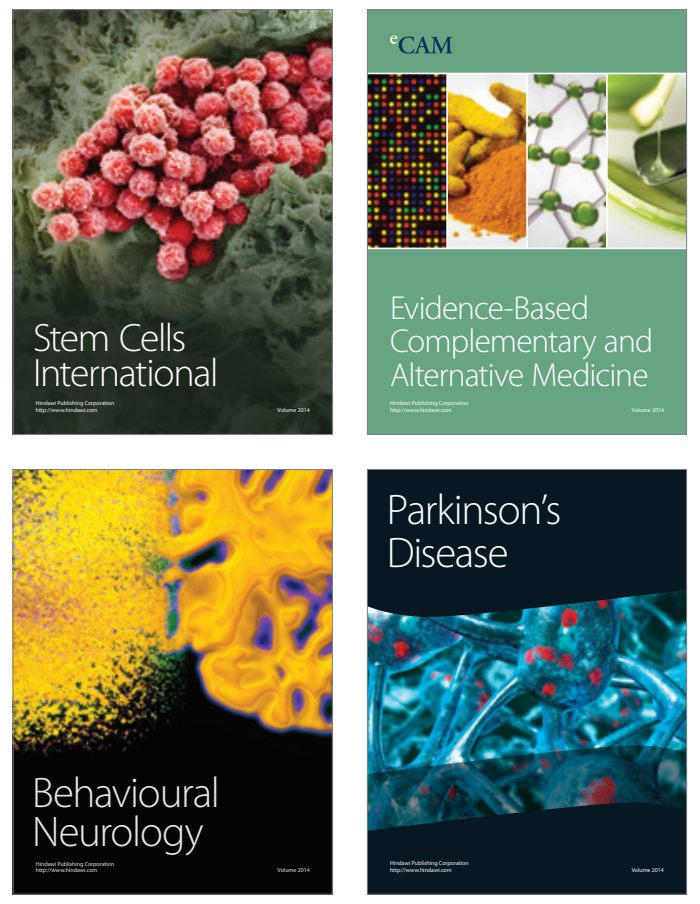
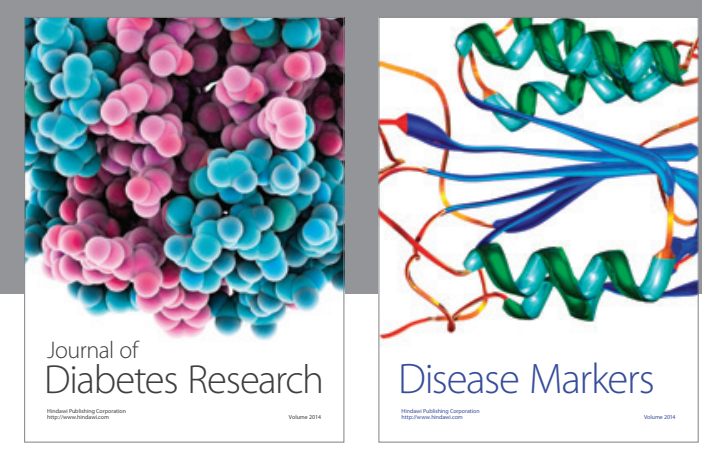

Disease Markers
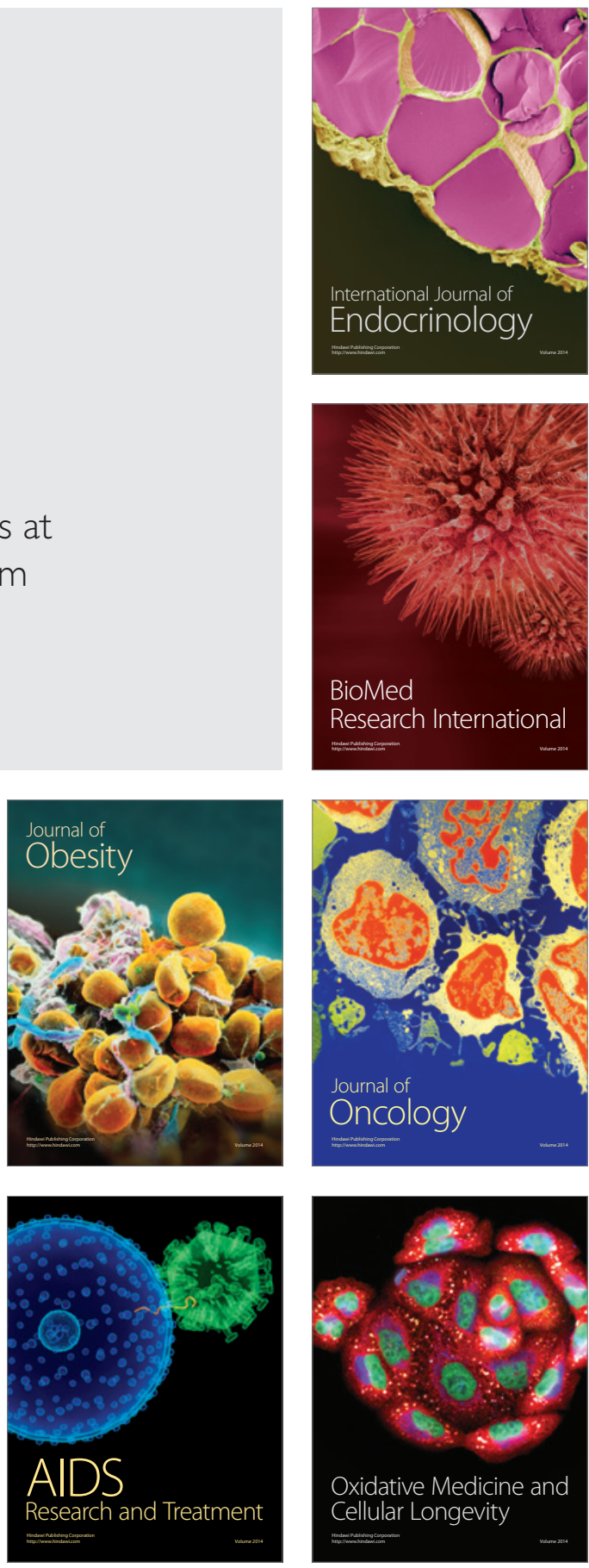